\title{
EDUCAÇÃO SUPERIOR E EDUCAÇÃO BÁSICA NOS INSTITUTOS FEDERAIS: A VERTICALIZAÇÃO E A CAPILARIDADE DO ENSINO A PARTIR DA AVALIAÇÃO DOS DOCENTES
}

\author{
Alexandre Maia do Bomfım; Giselle Rôças \\ alexandre.bomfım@ifrj.edu.br; giselle.rocas@ifrj.edu.br \\ Instituto Federal de Educação, Ciência e Tecnologia do Rio de Janeiro
}

DOI: 10.15628/rbept.2018.6697

Artigo submetido em dez/2017 e aceito em mar/2018

\section{RESUMO}

Os dados apresentados nesse artigo integram uma pesquisa maior sobre a importância da verticalização, a capilaridade e a compreensão de como (e se) ocorre a convivência da educação básica (ensino médio técnico) com a educação superior (graduação e pós-graduação) nos institutos federais. Os autores já abordaram tais questões a partir do seu próprio instituto, o IFRJ, entrevistando diferentes atores daquela comunidade. Depois investigaram o assunto a partir dos gestores de outros institutos que se disponibilizaram a responder as enquetes, e nesse momento, buscam alcançar a compreensão dos 87 docentes que participaram da pesquisa. Após a análise dos dados, os autores identificaram cinco "tipos-ideais" de respostas envolvendo aspectos sobre o papel e a importância da verticalização e da capilaridade dos institutos federais. Os autores concluem, conjuntamente com os docentes dessa etapa atual da pesquisa, mas também acompanhando os gestores e colegas de instituto, que a melhor chance da verticalização se dá a partir da inclusão efetiva da Pesquisa, em especial, mas também da Extensão (compreensão dos autores), despertando nos alunos o interesse pelos estudos e a permanência no sistema educacional, saindo dele apenas quando completar os seus estudos.

PALAVRAS-CHAVE: institutos federais, políticas públicas educacionais, verticalização do ensino, educação profissional e tecnológica, pesquisa-extensão. 


\title{
HIGHER EDUCATION AND BASIC EDUCATION IN FEDERAL INSTITUTES: THE VERTICALIZATION AND CAPILARITY FROM TEACHER PERSPECTIVE
}

\begin{abstract}
The data presented in this article are part of a larger research on the role of verticalization, capillarity and understanding of how (and if) the coexistence of basic education (technical high school) with higher education (undergraduate and postgraduate) occurs in institutes federal government. The authors have already addressed such issues from their own institute, the IFRJ, interviewing different actors in that community. Then they investigated the matter from other institutes" directors that were available to respond to the polls, and at that moment, they seek to reach the understanding of the 87 teachers who participated in the research. After analyzing the data, the authors identified five "ideal types" of responses involving aspects about the role and importance of verticalization and capillarity of federal institutes. The authors conclude, together with the teachers of this current stage of the research, but also accompanying the directors and their institute's colleagues, that the best chance of verticalization comes from the effective inclusion of Research in particular, but also from the Extension (authors comprehension), arousing in students the interest in studies and permanence in the educational system, leaving it only when they complete their studies.
\end{abstract}

KEYWORDS: federal institutes, educational public policies, verticalization of education, professional and technological education, research-extension.

\section{APRESENTAÇÃO}

Antes de tudo, vale trazer a con-textualização literal deste artigo. Ele é a terceira parte de uma pesquisa sobre a atual realidade dos Institutos Federais (IF), prestes a completar 10 anos após sua implementação com a Lei 11.892 de 2008 (BRASIL, 2008). A seguir, didaticamente, vamos recuperar alguns elementos dos dois textos anteriores, lembrando ao leitor que apresentamos apenas alguns teasers sobre ambos, não os dispensando da leitura.

\section{Prólogo 1: uma panorâmica}

No ensaio "O Convívio da Educação Superior com a Educação Básica nos Institutos Federais: perderemos essa oportunidade?" (BOMFIM, 2017) nos propomos a avaliar aquilo que potencialmente parecia mais característico e inovador nos IF, em relação às Universidades: a possibilidade concreta da verticalização, o convívio entre a Educação Superior (ES) e a 
Educação Básica (EB). Nessa primeira parte, um pouco mais panorâmica do que a seguinte, apresentamos o projeto da verticalização, encontrando várias defesas ao seu favor (advindos tanto das referências teóricas quanto dos depoimentos colhidos entre gestores, servidores e discentes), no mesmo momento que tentávamos apreender quais seriam os maiores obstáculos para sua realização. Vimos que havia toda uma desconfiança sobre a tarefa atribuída aos IF assumirem a ES, apesar da existência da graduação ser uma realidade em todos os campi que já integravam a rede como Centro Federais de Tecnológica (CEFET). Independentemente do debate que isso envolveu, o fato foi que os IF assumiram a "formação de professores" tanto no nível da graduação com as licenciaturas, quanto no seu prosseguimento temático na pós-graduação lato e stricto sensu (PEREIRA e RÔÇAS, 2017). Como também mantiveram uma tendência desde os CEFET de continuar com os Cursos Superiores de Tecnologia (CST), sendo necessário avaliar essa Educação Superior (ES) dos IF do ponto de vista da convivência com a educação básica (EB). Porém, apesar de prevista em lei, a verticalização apresenta controvérsias, pois

\footnotetext{
[Um] ponto negativo [à verticalização] (...) recai principalmente sobre os servidores que parecem possuir reflexões sacralizadas, escolásticas, a respeito do papel dos IF, independemente de serem servidores (...) mais ou menos experientes. $\mathrm{Na}$ verdade, os depoimentos negativos ou com ponderações críticas estão confirmando que principalmente entre os servidores estão os maiores problemas, os maiores entraves, do convívio entre os níveis de ensino, do que em relação aos estudantes. Parece que o diálogo mais desenvolvido tem sido entre discentes e discentes, todos os outros ainda estão travados (entre docentes e docentes, docentes e discentes, docentes e gestão, gestão e discentes...) (BOMFIM, 2017, p. 109).
}

Apesar de muitos servidores e discentes almejarem a realização da verticalização, pareceunos que os discentes, parte que com menos possibilidade imediata de implementar as políticas, são os atores que mais tem debatido e contribuído para isso.

Nossa reflexão, tinha uma pressuposto-de-trabalho, que se alinhou as nossas referências e, principalmente, aos depoimentos que coletamos:

(...) de que é possível realizar educação de qualidade, por conta de uma relação simbiótica (benéfica para os dois) entre a Educação Básica ea Educação Superior", através de uma Educação Científica do Ensino Médio até a pós-graduação stricto sensu dentro de uma mesma Instituição (BOMFIM, 2017, p. 115).

Entretanto, é essencial que essa seja uma meta, não se restringindo apenas a oferta dos distintos níveis de ensino, pois há o risco de se restringir a isso, caso sua materialização não 
for insistentemente perseguida. Enfim, outra inferência que alcançamos, juntamente com os depoentes, foi que: seriam os gestores, neste momento, com mais potencialidade para fazer algo mais substancial pelo melhor convívio entre ES e EB. Isso foi mote para o segundo artigo: apreender a práxis dos gestores.

\section{Prólogo 2: os gestores}

Destarte, a segunda parte de nossos estudos resultou no artigo "Educação Superior e Educação Básica nos Institutos Federais: avaliação da verticalização de ensino com seus gestores" (RÔÇAS, BOMFIM, 2017). E o que fizemos e o que encontramos aí?

Primeiramente tentamos dar mais densidade conceitual ao que seria "verticalização", para depois "avaliar a verticalização do ensino com e a partir dos gestores (...)" (RÔÇAS, BOMFIM, 2017, p. 52). Assim, alcançamos essas inferências, a seguir.

$\checkmark$ A compreensão que tudo isso aconteceu de forma muito rápida para ser assimilada, até mesmo para os gestores:

"Cefetizamos" as escolas técnicas federais e, cerca de 10 anos depois, "ifetizamos" os CEFETs, com a expansão da Rede Federal em tempo recorde e capilaridade intensa, e nesse ínterim queremos apresentar uma identidade consolidada, apesar de termos ampliado o quadro de servidores em quantitativos exponenciais, sem ter a devida acolhida e preparo de todos, em especial do docente que deve atuar em todos os níveis e modalidade de ensino (ibid. p. 58).

$\sqrt{ }$ Uma contradição, em que os gestores se apresentavam a favor da verticalização, apoiando-a na maior parte das vezes, mas sem a contrapartida de implementar ou mesmo sugerir ações para efetivá-la.

$\checkmark$ De que a verticalização só possuía um elemento mais concreto, o encontro no mesmo espaço entre estudantes secundaristas e do superior. "Até aqui, parece que há único elemento de convergência entre os estudantes é a utilização da mesma estrutura física dos Institutos, mas em períodos diferentes" (ibid. p. 61).

$\checkmark$ De que, mesmo esse único elemento concreto sobre a verticalização, é muito incipiente, pois embora no mesmo espaço, os gestores que consideravam esse convívio "tranquilo" promoviam basicamente sob a perspectiva do "efeito Feitiço de Áquila permite que poucos alunos do médio encontrem, ainda que por instantes, os alunos da graduação, mas com uma convivência temporal bastante limitada" (ibid. p. 60). Constamos então que não é feito algo de concreto no sentido da verticalização, pois muitos segregam os níveis de EB e ES em distintos momentos do dia.

$\checkmark$ Por fim, após um percurso por autores críticos dentro da área de Educação (cf. RÔÇAS, BOMFIM, 2017) e apesar de termos concluído que: “(...) "idealmente" os gestores apontam que seria muito bem-vindo o encontro entre a Educação Básica e a Graduação (...) o fato é que a materialização da verticalização ou encaminhamentos para isso praticamente não ocorrem" (ibid. p. 67), continuamos a defender a verticalização. 
$\sqrt{ }$ E continuamos a defender em nome de um "Instituto Unitário":

[Um Instituto] que se oponha aos vários dualismos da educação, que se oponha à divisão entre formação técnica e propedêutica, entre a escola para trabalhadores e a escola dos mais abastados, entre ciências naturais e ciências humanas, entre periferia e centro (ibid. p. 68).

$\checkmark$ Claro que sem camuflar vários problemas reais e urgentes, tais como: implementar a capilaridade da rede (uma face esperada para o IF em paralelo à verticalização); inadequação de docentes em trabalhar em diferentes níveis de ensino; da própria disputa entre os professores por espaço, por suas equipes, etc.; dos problemas com identidade (uma parte dos professores devem ser exclusivos ou pelo menos se dedicar mais a um curso?; etc.

Ao final do segundo artigo, deixamo-nos uma questão: pode a verticalização já ter obtido vícios ou ter perdurado muito tempo ineficazmente, ao ponto de não ser mais de interesse dos trabalhadores? Ainda nessa parte continuamos a defender que sim, dizendo precisamente que a "escola dos trabalhadores" poderia sim ter o convívio entre a EB e ES e que não precisariam ser separadas. É a partir das compreensões apresentadas que avançamos para a terceira (mas não necessariamente o último) etapa de nossa investigação, vamos diretamente aos docentes, tentando complementação à reflexão que viemos fazendo até agora. Não obstante, acrescentaremos uma questão meta-teórica aqui, sobre a potencialidade da "verticalização": a verticalização não seria uma quimera'? A expansão, a proposta de capilaridade para os IF, também não seria? Algo que teoricamente a maior parte de nós quer e acredita, mas que no cotidiano não convergimos práticas para sua realização.

\section{AGORA COM OS DOCENTES: NOSSA ETAPAS DA PESQUISA}

Já atualizado nosso percurso até aqui, com dois trabalhos com um substancial leque de conclusões e considerações, uma pergunta de ordem prática nos acompanha: encontraríamos algo diferente entre os docentes do que vimos a partir do estudo mais panorâmico e/ou com os gestores? De qualquer forma, assumimos esse risco porque precisávamos imediatamente de dois movimentos: (a) organizar o percurso que desejamos fazer desde o início (que pressupunha passar por um estudo panorâmico, por outro com os gestores, depois com os professores e, conforme fosse, pelos discentes e técnicos-administrativos); (b) definitivamente, constatar nessa fase de pesquisa, a partir das colocações dos professores que aceitaram nosso convite e provocação, se há a possibilidade de reflexões novas (e talvez fechar a pesquisa).

Uma grande rede de relacionamento (distribuição do link da enquete ${ }^{2}$ por email, What's app

\footnotetext{
1 Estamos com uma das definições do Houaiss: "Quimera (p. ext.): produto da imaginação humana, sem consistência ou fundamento real; ficção, ilusão" (HOUAISS, 2017).

2 https://docs.google.com/forms/d/1BaaZGjigftJThono6nef51IFUIRo2ihm_QqBvirvT6o/edit?ts=5977d93a- $\quad$ sinta-se à vontade para contribuir, sendo docente, discente ou servidor. Basta identificar em qual categoria está.
} 
e Messenger). Também buscamos viabilizar o acesso aos docentes através da SETEC-MEC e do CONIF, apesar dos diversos e-mails enviados, nenhuma resposta foi obtida. Particularmente, julgamos uma pena tal omissão, pois compreender a Rede Técnica Federal a partir da própria rede possibilita uma compreensão mais afinada com a realidade vivida, e quiçá com menos préconceitos. Usando a rede já citada, alcançamos 15 Institutos Federais (IF) dos 38 existentes, com pelo menos um IF em cada uma das cinco regiões do Brasil, contabilizando a participação de 87 professores, incentivados a responder as perguntas que se seguem, além da parte da ficha técnica (e-mail, nome, instituição, cargo, área/disciplina):

I. Distância, em quilômetros $(\mathrm{km})$, entre seu endereço de moradia e o campus onde trabalha?

II. Buscamos aqui obter mapear como a capilaridade (principalmente a capacidade de interiorização dos IF) se materializa de maneira prática e cotidiana para os professores que não moram ou não migraram para perto de seu Instituto.

III. Nível (Níveis) de ensino em que atua?

IV. Desejamos saber o quanto o professor transita em variados níveis de ensino (se está nada, pouco ou muito dividido).

V. De maneira geral, como está a verticalização no IF em que atua, essa missão de estabelecer o convívio entre a Educação Superior e a Educação Básica (considere pontos fortes e pontos fracos)? Quais são as perspectivas para esse convívio dentro dos IF?

VI. Que ações (e por parte de quem) devem ser realizadas, em relação à verticalização, considerando um futuro imediato e de médio prazo?

VII. Objetivamos obter uma avaliação por parte do docente em relação à verticalização, para agora e para o futuro, apontando quem seria o maior responsável pela ações e políticas de consolidação.

VIII.Você conhece a Lei 11.892 de 2008 que “Institui a Rede Federal de Educação Profissional, Científica e Tecnológica, cria os Institutos Federais de Educação, Ciência e Tecnologia, e dá outras providências"?

IX. Que avaliação GERAL faz da Lei? Considere o que pode/deve alcançar a Lei, em relação ao que provavelmente não pode/deve alcançar.

$X$. Buscamos mapear o grau de conhecimento dos docentes acerca da lei de criação dos IFs, além de obtermos uma avaliação sobre a lei que implementa os IF do ponto de vista dos docentes.

XI. Por fim, independentemente do conhecimento que possui da Lei 11.892/2008, como avalia a proposta de capilaridade (capacidade de interiorização dos IF)?

XII. Com essa pergunta vislumbramos a possibilidade de avaliarmos como a a capilaridade é compreendida pelos docentes.

XIII.Gostaria de compartilhar esse pequeno questionário com mais um colega DOCENTE da Rede? Registre o e-mail dele aqui. 
Pretendíamos garantir a continuidade da pesquisa, com a indicação de outros colegas do mesmo IF ou de outros.

Considerando também a ficha técnica, pode-se dizer que colhemos um material muito significativo, tanto pela participação expressiva (87 docentes), quanto pela qualidade (15 instituições representadas e por várias áreas/disciplinas), mas, principalmente pelo número extenso de respostas. Este artigo não pretende esgotar esse material, o qual possivelmente será utilizado para outras possibilidades de reflexão dada a riqueza das informações coletadas

\section{ASPECTOS GERAIS DOS RESPONDENTES}

Todos os docentes que responderam eram da Carreira de Magistério do Ensino Básico, Técnico e Tecnológico (EBTT)³ , de 15 instituições de várias regiões do Brasil (Tabela 1) e de diferentes áreas/disciplinas (abarcando desde a área de Administração, Humanidades, Ciências Naturais, Linguagens, até às técnicas mais específicas).

Tabela 1: Instituições de origem dos docentes respondentes e quantitativo de respostas por IFES.

\begin{tabular}{|c|c|}
\hline Instituição de origem & Docentes respondentes \\
\hline IFRJ & 35 \\
\hline IFFluminense & 8 \\
\hline IFSP & 6 \\
\hline IFBA & 5 \\
\hline IFAC & 4 \\
\hline IFAM & 4 \\
\hline IFES & 4 \\
\hline IFGoias & 4 \\
\hline IFRR & 4 \\
\hline CEFET-MG & 3 \\
\hline IFGoiano & 3 \\
\hline UTFPR & 3 \\
\hline IFRN & 2 \\
\hline IFFarroupilha & 1 \\
\hline IFSergipe & 1 \\
\hline
\end{tabular}

Fonte: elaboração própria, a partir da pesquisa realizada.

Em relação à distância entre a moradia e o local de trabalho, 48 dos respondentes disseram morar até $15 \mathrm{~km}$, outros 17 deles entre $15 \mathrm{~km}$ e $30 \mathrm{~km}$, por fim, 22 estão distantes para mais de

3 O que não é óbvio, pois há professores na Rede que são da Carreira do Magistério Superior (caso dos dois autores deste artigo). 
$35 \mathrm{~km}$. Vale a pena ver isso em termos de porcentagem (Tabela 2). Sabemos que em algumas cidades brasileiras o escoamento do trânsito e os transportes públicos são ruins, implicando em um gasto de tempo no deslocamento alto ainda que morando perto do trabalho. Partindo dessa compreensão nem sempre morar perto significa chegar rápido em seus destinos profissionais. Entretanto, é certo que aqueles que moram longe, bem longe (acima de $90 \mathrm{~km}$ ) dos seus campi, sofrem cotidianamente com o desgaste do trânsito/translado, com ou sem horário de rush. Reconhecer tal situação é essencial para o sucesso da capilaridade da rede dos Institutos, pois precisamos compreender que a interiorização provoca alguns movimentos que precisam ser considerados em sua completude: 1) levar educação de qualidade, pública e gratuita para regiões que outras redes não alcançam, oferecendo cursos que vão desde o ensino médio até o stricto sensu (ao menos potencialmente); 2) alterar a dinâmica das comunidades do entorno, podendo impactar na economia de algumas cidades, com expectativa de crescimento futuro; 3) alterações na organização das famílias dos docentes, que ainda não adequaram sua vida à nova realidade, portanto ainda residem longe do trabalho, ou mesmo que não é possível realizar tal adequação por questões logísticas/educacionais/profissionais de outros membros das famílias. Ou seja, os IF têm alcançado cada vez mais cidades do interior, algumas de porte pequeno, com baixo grau de desenvolvimento ainda, considerar a mudança de todos que vivem com o docente nem sempre é possível.

Tabela 2: Distância entre moradia e campus do IF no qual o docente desenvolve suas atividades profissionais.

\begin{tabular}{|l|l|}
\hline Distância & Número de respondentes (em porcentagem) \\
\hline Até $12 \mathrm{~km}$ & $55,17 \%$ \\
\hline Entre 15 e $30 \mathrm{~km}$ & $19,54 \%$ \\
\hline Entre 35 e $90 \mathrm{~km}$ & $12,64 \%$ \\
\hline Entre 100 e $370 \mathrm{~km}$ & $12,64 \%$ \\
\hline
\end{tabular}

Fonte: elaboração própria, a partir da pesquisa realizada.

Ressaltamos aqui a importância de avaliarmos em breve se esses números (que expressam a distância entre moradia e trabalho) diminuirão com o tempo. 0 ideal é que diminua, nunca totalmente, mas progressivamente até uma minoria, para aqueles que moram distantes. Entretanto, é comum que os servidores façam o concurso, cientes da lotação das suas vagas expressas em edital, após aprovação e posse, iniciam buscas para transferência, permutas ou remoção via editais internos. Em muitos casos, somente após esse movimento estar consolidado é que os perfis para os códigos de vagas disponíveis são traçados e novos editais de seleção são publicados. É importante ressaltar que não somos contrários a tais estratégias, mas do ponto de vista da consolidação do corpo de servidores de um campus no interior, elas não favorecem a capilaridade da rede. 
Sobre a "capilaridade" vale entender que pode acontecer sob duas formas. Uma, que já mencionamos antes, se dá por um movimento de interiorização dos IF, quando construídos e estimulados a se desenvolver distante da capital do Estado. A segunda forma é quando são instalados relativamente próximos à capital, geralmente na região metropolitana, algumas vezes em áreas suburbanas e com fronteiras de violência bem delimitadas. Nosso Instituto Federal de Educação, Ciência e Tecnologia do Rio de Janeiro (IFRJ), onde também conseguimos mais respondentes para esta pesquisa, é um bom exemplo disso. 0 mais antigo dos campi fica na capital, o campus Rio de Janeiro (conhecido como campus Maracanã), o segundo foi o do campus Nilópolis, na Baixada Fluminense. Com a expansão, muito estimulada pela Lei 11.892, o IFRJ hoje tem mais 13 campi, além dos citados (que podemos definir como "i" quando for "interior" e " $p$ " quando for "periférico", relativamente próximo da capital): Arraial do Cabo (i), Belford Roxo (p), Duque de Caxias (p), Engenheiro Paulo de Frontin (i), Mesquita (p), Niterói (p), Paracambi (i), Pinheiral (i), Realengo (p), Resende (i), São Gonçalo (p), São João de Meriti ( $p$ ) e Volta Redonda (i). Pode-se perceber que essas duas características no IFRJ estão em equilíbrio. Porém, apesar de termos campi periféricos, relativamente próximos sem a necessidade de mudança de domicilio, a baixa qualidade da malha viária e de transporte público no nosso estado, aliada as condições de violência também provocam o movimento migratório dos servidores.

No que a tange a verticalização destacamos a importância do grau de identificação do docente em relação a um curso ou quanto se desdobra em vários trabalhando simultaneamente dentro de um período, vale observar a Tabela 3 abaixo.

Tabela 3: Envolvimento do corpo docente por simultaneidade de níveis de ensino (Médiotécnico, graduação e/ou pós-graduação).

\begin{tabular}{|l|l|}
\hline Quantidade de níveis de Ensino que atua & Número de docentes \\
\hline Em apenas um nível de Ensino & 23 \\
\hline Em dois níveis de Ensino & 34 \\
\hline Em três níveis de Ensino* & 33 \\
\hline
\end{tabular}

Fonte: elaboração própria, a partir da pesquisa realizada.

Observando o quadro é possível apreender que somente 23 docentes de 87 (menos de 1/3) estão alocados em único nível, não necessariamente um único curso dentro desse nível. Isso significa que os docentes estão experimentando, na prática, uma faceta da verticalização, desse convívio entre diferentes níveis de ensino. Não dá para avaliar se isso é bem organizado

\footnotetext{
* Preferimos não distinguir formatos ou modalidades, não distinguimos, por exemplo, Médio-Técnico em EJA para Médio-Técnico Regular ou este para Médio-Técnico EaD. Para o Ensino Superior, distinguimos graduação em relação à pós-graduação. Porém, a pós não distinguimos entre lato e stricto sensu. A razão era saber como estavam alocados os docentes nessas grandes matrizes: educação básica, graduação e pós-graduação, muito por conta de suas especificidades, seus desafios, sua organização dentro da Educação Brasileira.
} 
(provavelmente não, pois deve ser para cumprimento de carga-horária), se corresponde às demandas dos próprios cursos ou mesmo dos próprios professores, se respeita áreas temáticas, disciplinas, planejamentos, etc. Ainda que nas Universidades alguns professores estejam em dois dos níveis da tabela 3 (em geral na graduação e na pós), pode-se dizer com segurança que não possuem mais de um terço de seus professores em três níveis de ensino (básica, graduação e pós ${ }^{4}$ ). Não obstante, isso é motivo de orgulho ou preocupação para os IF? Ainda que desejemos estar nos três níveis de ensino, desejamos isso também para maior parte do corpo docente? Isso não o fragmenta? Isso não the retira a identidade, não atrapalha inclusive a própria identidade dos cursos? Como estimulamos o sentimento de pertença de um docente em relação a um curso/nível, se constantemente sua carga horária é alocada nesse ou em outro curso dependendo das necessidades institucionais?

\section{SOBRE AS RESPOSTAS QUALITATIVAS}

Numa aproximação das respostas de nossos 87 docentes entrevistados, podemos perceber (justificaremos nossa interpretação com trechos, a seguir) que a pergunta principal que fizemos sobre a verticalização (seus pontos fortes e fracos) engendrou cinco "tipos-ideais" ${ }^{5}$ de respostas:

1) de que a verticalização acontece sim, porque é visível na estrutura do IF, em questão. Encontra-se positivamente nos três níveis de ensino (e vai avançar) porque há momentos (como nos eventos) para os encontros de todos os estudantes;

2) não há verticalização ou é uma verticalização estanque, pois, o IF oferece turnos diferentes para cada nível de ensino, não havendo oferta dos três níveis no campus em que se trabalha;

3) a verticalização é precária por conta de um só item.... Neste momento é comum atribuir a culpa sobre um item só, alguns legítimos, mas geralmente muito ideológicos e que valeria para explicar qualquer problema do IF, aqui encontramos as respostas hipostasiadas, idiossincráticas, aventureiras e por vezes até preconceituosas para explicar a precariedade da verticalização;

4) a verticalização não dará certo (ou nem deveria ser prioridade), os respondentes percebem o que representaria para os IF, mas ressaltam mais a impossibilidade de enfrentar os percalços para sua realização;

5) A verticalização dará certo, desde que... percorra alguns dos caminhos propostos.

4 Algumas universidades possuem colégios de aplicação, e somente nesses casos, uma parcela dos docentes experimenta a possibilidade de atuar de forma verticalizada essa atuação desde o ensino médio, passando pelas licenciaturas e chegando a pós-graduação. Não podemos deixar de citar também o caso do Colégio Pedro II, localizado na cidade do Rio de Janeiro, que integra a Rede Federal de Educação Profissional, Científica e Tecnológica experimentando em seu cotidiano os efeitos da verticalização.

5 "Tipo Ideal” [Dicionário de Sociologia]: "As construções de tipo ideal fazem parte do método tipológico criado por Max Weber que, até certo ponto, se assemelha ao método comparativo. Ao comparar fenômenos sociais complexos o pesquisador cria tipos ou modelos ideais, construídos a partir de aspectos essenciais dos fenômenos. A característica principal do tipo ideal é não existir na realidade, mas servir de análise de casos concretos, realmente existentes. Cf. https://pt.slideshare.net/andre155021/dicionario-de-sociologia 
Vamos com exemplos de depoimentos para cada um desses tipos. Vamos com dois que caracterizem o primeiro:

\begin{abstract}
Acredito que o IF Goiano é referência entre os Institutos Federais no quesito verticalização. Ele foi o primeiro Instituto Federal a oferecer ensino a nível de Doutorado no Brasil. Hoje, ofertamos Ensino Médio Integrado, concomitante/ subsequente, graduação (licenciaturas e bacharelados engenharias), Pósgraduação Lato sensu, vários Mestrados e Doutorado - (Respondente 7).

No meu IF o processo de verticalização já ocorre há alguns anos, em um dos nossos eixos de trabalho (no caso, informática) e tem sido dado continuidade a esse processo, através da proposição de novos cursos. Entre os alunos do eixo de informática, apesar dos cursos ocorrerem em turnos diferentes, no momento em que ocorrem eventos que todos se juntam, a convivência ocorre de forma razoavelmente tranquila e às vezes, a integração a partir desses eventos é muito boa - (Respondente 9).
\end{abstract}

Essas passagens demostram que aqui há a verticalização porque há a oferta dos cursos e que o encontro entre os estudantes vai ocorrendo com "tranquilidade" nos eventos, apesar dos turnos diferentes.

O segundo "tipo ideal" (em que não se enxerga a verticalização) é ilustrado com as passagens abaixo:

Por enquanto, ainda não tem acontecido na área na qual trabalho, vejo em algumas áreas, mas ainda é bem precária - (Respondente 10).

Ainda em estágios iniciais, pois há somente um curso superior no campus que atuo - (Respondente 32).

Não verifico muito convívio uma vez que o ensino superior ocorre basicamente de manhã, o médio-técnico pela tarde e o Técnico subsequente pela noite (Respondente 63).

Nos campi do interior do estado isso ainda não foi efetivado. Tem ficado restrito ao médio técnico e a graduação. As pós-graduações estão bem travadas. Ocorrem bastante FICs - (Respondente 36).

Agora ao terceiro "tipo ideal" acredita que ainda há um ponto que atrapalha a verticalização, constituindo no grupo de resposta mais "aventureiro":

[A verticalização] Ainda não está completa, apenas iniciada. 0 ponto forte é um mesmo grupo de professores que pode interagir em diversos níveis de ensino. 0 ponto fraco é a soberba de alguns professores que se recusam a trabalhar no 
Ensino Médio Técnico por se acharem professores de Graduação ou Pós. No entanto, são todos (com pouquíssimas exceções) do EBTT - (Respondente 41). Acho uma excelente relação entre o técnico e a graduação em nosso campus. Já a Pós-graduação guarda uma boa distância pelas características de seus alunos e atividades de pesquisa. As perspectivas de mudança nessa situação são na minha opinião pouco prováveis de mudar - (Respondente 56).

Acho que não foi atingido, pois temos mais um "espírito de escola" do que um espírito que una escola e universidade. Acho que acabaremos indo buscar saídas segmentadas - (Respondente 53).

Vejo mais prontos fracos do que fortes, uma vez que considero perniciosa a convivência de adolescentes com os adultos - (Respondente 6).

Sem entrarmos no mérito das respostas, é possível perceber que as críticas que foram feitas não se atrelam imediatamente à verticalização, mas poderia servir para qualquer outro problema ou desafio para os IF (em relação à capilaridade, por exemplo), pois o que se apontar mesmo é o problema que precederia à verticalização (a soberba dos professores, as especificidades dos alunos da pós-graduação, o "espírito de escola", a perniciosa convivência de adolescentes e adultos). Não dá para avaliar se é isso que impede realmente a realização da verticalização, mas dá para dizer que devemos sempre ter cuidado em não misturar "causa" com "consequência" ou confundir problemas diferenciados.

O quarto "tipo ideal" é mais pessimista, não enxerga a verticalização como algo prioritário ou emergencial, enxergando sempre o "copo meio vazio", apesar de reconhecer situações nas quais ela ocorra minimante:

Penso que este convívio tem deixado muito a desejar. Apesar de habitarmos o mesmo espaço físico, pedagogicamente nada é discutido e compartilhado (Respondente 48).

Muito incipiente. A graduação acontece no turno da noite e a maior parte do EMT acontece durante o dia. Os alunos da graduação têm dificuldades em participar de atividades durante o dia e os alunos do EMT têm dificuldade em participar de atividades no turno da noite (distância da moradia e dificuldade no transporte). Não vejo pontos negativos na verticalização, mas dificuldades na sua materialização no campus. Nas poucas situações em que ocorre, traz crescimento (projetos, monitorias, eventos) - (Respondente 58).

Há uma boa verticalização entre cursos técnicos e superiores. Porém, não considero a verticalização essencial para a atuação de um campo na área de Ensino. Considero mais a importância do aproveitamento de recursos humanos 
e do aproveitamento da vocação e das necessidades que apresentam a região no qual o campus se encontra instalado - (Respondente 80).

O quinto "tipo ideal" funciona como de forma mais otimista, percebendo que o "copo está mais cheio", identificando a importância da verticalização desde que alguns elementos sejam considerados:

Ainda persiste uma divisão entre os níveis, tanto no que se refere às ações desenvolvidas quanto à atuação docente. Há uma cultura de que lecionar no Ensino Superior tem mais prestígio. O próprio amadurecimento do processo, que ainda é recente, de construção da identidade dos Institutos Federais, tende a superar essa divisão. É muito positiva e ao mesmo tempo desafiadora a proposta de se trabalhar com níveis de ensino com características tão próprias, mas para a atuação docente também representa um crescimento profissional. Para os IFs, se houver um esforço de se compreender a razão da sua própria criação e se voltar para o eixo da educação tecnológica, sem acentuar a divisão entre os níveis e oferecendo o melhor ensino público inclusive para a educação básica, a perspectiva é de valorização desse convívio, permitindo construir uma identidade particular e envolvendo ambos os níveis em um projeto de escola (Respondente 85).

Atualmente, ainda percebo que falta uma identidade para o Ensino Superior no IFRN. Muitas ações ainda são planejadas com o foco no ensino básico. Acredito que seja necessário um fortalecimento da Identidade do Ensino Superior no IFRN para que se aproxime mais das Universidades, através da reformulação de documentos e padrões específicos do ensino superior. A perspectiva é que o ensino superior dentro dos IF se consolide o mais breve possível através de uma atuação mais específica em cada área - (Respondente 72).

O que parece ser comum para maior parte desses "tipos-ideais" de respostas (apesar de algumas exceções) é não considerar um elemento previsto para o conceito de "verticalização" que seria: dar aos estudantes acesso a todas as etapas de ensino numa mesma instituição. É possível ressentir isso exatamente com essa passagem de Eliezer Pacheco, ex-secretário de Educação Profissional e Tecnológica do Ministério de Educação, intelectual orgânico favorável à expansão dos IF:

A verticalização, por seu turno, extrapola a simples oferta simultânea de cursos em diferentes níveis sem a preocupação de organizar os conteúdos curriculares de forma a permitir um diálogo rico e diverso entre as formações. Como princípio de organização dos componentes curriculares, 
a verticalização implica o reconhecimento de fluxos que permitam a construção de itinerários de formação entre os diferentes cursos da educação profissional e tecnológica: qualificação profissional, técnico, graduação e pós-graduação tecnológica (PACHECO, 2011 p. 24).

Um estudo apresentado em 2016, na Anped Regional-Sul, trazia também essa compreensão, de que muitas vezes a verticalização só alcança o patamar da oferta de níveis de ensino (QUEVEDO, 2016), não conquistando uma relação de fato entre os cursos, favorável ao discentes e com participação técnica e consciente dos servidores. Ou seja, a verticalização pensada de maneira a articular o conjunto de saberes e a expertise dos docentes e técnicos envolvidos, possibilita uma troca profícua que enriquece tanto o profissional formador como o que esta em formação.

Houve também a pergunta que buscava apreender junto aos docentes dois itens: quem mais deve ser responsabilizado pela verticalização e o que devemos fazer? De maneira geral, houve muito a responsabilização dos gestores diretos e dos governantes. Para muitos, quem realmente determina o fracasso ou sucesso da Lei 11.892 são os governantes, havendo pouco ou nenhum espaço para os demais atores envolvidos. Da mesma forma que a Lei veio de cima, sua realização parece que terá que vir de cima também.

[A responsabilidade é] Do Governo Federal. Os institutos precisam de verbas para melhorar suas estruturas, precisam de vagas para docentes e técnicos administrativos. A expansão dos IFs precisa continuar, porém o atual governo está indo na contra-mão de tudo isso. Estamos a caminho do sucateamento (Respondente 7).

Realmente não dá para discordar dessa visão, pode ser muito ingenuidade nossa achar que políticas internas de um Instituto podem se contrapor aos ditames advindos do Palácio do Planalto ${ }^{6}$. Não obstante, não é de agora os problemas da verticalização ou da capilaridade para os IF, pois vem desde os CEFET. Isso está presente em Rôças e Bomfim (2017) quando trazem a questão de que éramos escolas federais técnica ou agrotécnicas, que foram "cefetizadas" e depois "ifetizadas", as graduações já eram um desafio posto na época dos CEFTEs, com os IFs o principal desafio foi a autonomia das gestões dos campi (ANJOS, RÔÇAS, no prelo) e a capilarização de forma acelerada. Sabíamos fazer um ensino médio técnico de excelente qualidade, fomos tirados de nossa zona de conforto ao sermos "convidados" a ofertar graduação e pós-graduação. Ainda engatinhando em nossa nova feição, "nos mudaram" de

6 Sobre isso, vale lembrar Bourdieu: Penso que, em sociologia, muita gente trabalha em caixas vazias. Porque o essencial dos fatores explicativos está do lado de fora, muito longe. Por exemplo: você estuda os problemas escolares num subúrbio, mas o problema está na Escola Nacional de Administração (ENA). Se você estuda violência numa favela ou num subúrbio de Amsterdã, o problema pode estar no FMI. Sei que estou exagerando, mas acredito que é preciso chamar a atenção para esses fatos (BOURDIEU, 2002, p.33). 
novo! Ou seja, não é somente neste governo que esses desafios estavam sendo postos, a Lei já caminha para 10 anos (considerando a cefetização chega a 20 anos, pelo menos). Ou seja, a sua materialização (ou não) deve ser avaliada, devem ser perseguidos ao menos seus vestígios.... Os IF não caminham nessa direção? E por outro lado, há também itens que os IF precisam considerar, precisam tentar implementar, pois não adianta ficar sempre reclamando das ações do governo federal, nem sempre o mesmo, nem sempre atento a todos os passos que podemos fazer (e contradizer). Podemos optar também pela subversão de alguns pontos. Afinal, se somos excelentes no que fazemos, se nossos alunos de EMT obtém excelentes resultados no PISA (PISA, 2015), equiparando-se a países europeus. Assim porque precisamos acatar algumas políticas "pequenas" como a nova proposta curricular para o ensino médio? Além do PISA há outros dados fornecidos por agências externas que comprovam que os institutos federais são ilhas de excelência no sistema público e gratuito, impactando de forma positiva na realidade de muitas famílias brasileiras, mas ainda assim não reagimos, nos deixando sempre a mercê das políticas públicas que "vem de cima" e correndo atrás dos novos ditames. Alguns professores viram isso também:

Este processo deveria estar considerado no PDI da Instituição e fazer parte da política departamental da Instituição - (Respondente 2).

Cotas para alunos oriundos dos nossos técnicos para nossas graduações (Respondente 44).

Os projetos pedagógicos dos cursos devem ser revisados para favorecer a integração aproximando estudantes dos diversos níveis em ações conjuntas (Respondente 45).

Por fim, um incentivo muito pertinente e (precisamos dizer logo) converge muito com a compreensão que possuímos para os IF. Foi muito recorrente entre os professores de que para haver a verticalização será necessário o reconhecimento da pesquisa e extensão dentro dos IF. Nós, autores desse artigo, reconhecemos essa via como a melhor chance de estabelecermos a verticalização. Porque é importante a compreensão de que a verticalização não pode se restringir ao Ensino, mas que deve extrapolar para compor a tríade - Ensino, Pesquisa e Extensão - de forma plena e, quiçá mais atuante, já que na estrutura dos IF, os projetos podem ser realizados de forma mais ágil, considerando que ainda não há os ranços e/ou corporativismos tão comuns nas universidades. Os IF não podem ser espaço apenas para a docência, mas também de pesquisa, porque não adiantará forçar a verticalização, se nossos alunos não desejarem continuar por uma graduação, por uma pós lato e por uma pós-stricto sem qualidade, sem horizonte acadêmico, sem possibilidade de inovar e construir conhecimento. A extensão também é importante, pois face a capilaridade que alcançamos, estamos muito mais próximos das demandas da comunidade no entorno dos campi, alcançando de forma mais rápida e talvez efetiva. Algo que o respondente 11 apontou: 
O eixo dos cursos técnicos não coincide com os cursos superiores oferecidos no campus. Em minha pesquisa de doutorado os dados revelam que os estudantes do médio almejam outras carreiras, principalmente medicina, direito e engenharias. Escolhem estudar EM [Ensino Médio] no IF pela qualidade do ensino.

Outro ponto interessante foi perceber que a maior parte dos professores também não se restringiu reivindicar "pesquisa aplicada", mas sim "Pesquisa" no seu sentido (e volume) máximo. E na contrapartida, também tomaram cuidado em defender o cuidado para que não haja castas fechadas de pesquisadores versus aqueles que "só dariam aula", porque hierarquizar os professores dessa forma não seria conveniente ao desenvolvimento do IF (e diríamos nem é salutar ao pesquisador, que antes de tudo é docente). Claro que é algo polêmico, pois pode ter reflexo em carga-horária docente (algo complicado para resolver em quase toda rede), mas vale reforçar que conceitualmente nos parece avançado.

No CEFET-MG a verticalização do ensino existe em sua totalidade, desde o ensino médio/técnico ate o doutoramento. É disponibilizada a oportunidade do aluno entrar no técnico e sair como doutor além de permitir a integração dos alunos destes níveis em pesquisas. Apenas, que algumas vezes o ensino técnico é menos valorizado que os níveis superiores - (Respondente 4).

Em processo de construção de uma nova cultura escolar e organizacional. Conflitos entre a cultura anterior de Escola Fazenda e ensino técnico agrícola com a cultura universitária e de pesquisa que relega o ensino a segundo plano de prioridade (Respondente 5).

Foi a melhor proposta de educação que o Brasil já teve: a existência dos Institutos Federais. A possibilidade de interiorização de cérebros, de conhecimento onde ele não chegava, as oportunidades que agora são oferecidas no interior e o quantitativo de regiões atendidas. Antes, só tínhamos Doutores em sala de aula somente nas capitais e em cursos superiores. Hoje, com os IFs podemos ver jovens tendo aula com equipes de professores na maioria Mestres e Doutores atuando tanto no ensino, quanto na pesquisa e na extensão. Vemos alunos concluírem o ensino médio integrado e entrar no mercado de trabalho plenamente preparados e vemos também esses mesmos jovens entrando em cursos de elite (como Medicina, Odonto, Direito, Engenharias, Farmácia...) nas melhores Universidade do País sem fazer se quer um cursinho [sic]. Não tem como negar, a política de Educação dos Institutos Federais é o que o Brasil precisa, não podemos deixar o governo acabar com ela em prol dos empresários 
da educação. Precisamos que a existência dos Institutos Federais seja uma política de Estado e não de governo - (Respondente 7).

Um estudo que considere "construção de uma nova cultura escolar e organizacional" talvez seja o nosso próximo passo, porque esse é o desafio que vem sendo posto para nós, da Rede Federal Técnica. É possível ver massa crítica e militância dentro dos IF, mas como consolidar isso de forma mais massiva? Como fazer com que "a melhor proposta de educação que o Brasil já teve..." (os IF) se aproxime mais das pessoas, atinja mais a classe trabalhadora? De maneira geral, estamos sempre a reboque das políticas de governo, ainda que guardemos alguma memória e ainda que consideremos certo percurso, somos muitos afetados pelas mudanças de concepção e de ações que oscilam junto à alternância de governo. Não obstante, ainda que sejam essas políticas de nível macro que realmente determinam (e continuarão determinando) nossa expansão, nosso desenvolvimento e qualidade, que projeto apresentamos (ou apresentaremos) à sociedade, nas oportunidades que tivermos? Planejar o futuro também nos parece importante e precisaremos fazê-lo.

\section{A GUISA DE UMA CONCLUSÃO}

Um dos docentes (respondente 11) apontou acima que nem sempre nossos cursos estão de acordo com os interesses de nossos alunos. Que, em várias ocasiões, os alunos completam o ensino médio técnico em um instituto federal, mas buscam outras carreiras, como medicina, direito, artes, jornalismo.... Mas esse chega a ser um problema? Talvez uma outra faceta da verticalização, pois será que só a compreendemos se for promovida e executada em sua integralidade dentro dos IF? Ou podemos ampliar nossa compreensão para uma verticalização à formação do aluno? Quando, por exemplo, esse aluno se percebeu pertencente a uma graduação e a uma pós-graduação.... Tomamos aqui a uma fala de um aluno de EJA do IFRJ presente em ANJOS e RÔÇAS (no prelo) que representa a importância da verticalização no resgate da autoestima e da formação de um cidadão:

Entrar num centro de educação federal através das portas do EJA... e depois... ter encarado uma faculdade, uma graduação no próprio instituto, não é uma coisa muito fácil né? Durante o meu percurso eu vi muitas pessoas saírem por diversos motivos, mas ter continuado essa trajetória é muito bom, porque você cria um laço. Eu tenho um laço aqui no instituto, mas em síntese é a agregação dos valores, isso é importante... isso é importante! (ANJOS e RÔÇAS, no prelo).

Retornamos aos questionamentos apresentados acima, nos quais buscamos compreender se a verticalização e a capilaridade da rede é (ou não) motivo de orgulho ou 
preocupação para os IF? Nós, autores, acreditamos em ambos. É orgulho, pois entendemos que podemos influenciar no curso da história, resgatando meninos e meninas que não se sentem pertencentes ao sistema educacional, em especial aquele que é de boa qualidade, possibilitamos um futuro melhor, formando cidadãos mais reflexivos, e buscando quebrar o paradigma de sermos uma escola pensada para os "desvalidos da sorte". Ainda assim, nos preocupamos sobre o como fazer. Afinal, as demais questões estão longe de serem resolvidas, ainda que façamos internamente algumas apostas. Perguntas de ordem prática, envolvendo questões de logísticas e de identidade, tais como: Ainda que desejemos estar nos três níveis de ensino, desejamos isso também para maior parte do corpo docente? Isso não o fragmenta? Isso não the retira a identidade, não atrapalha inclusive a própria identidade dos cursos? Como estimulamos o sentimento de pertença de um docente em relação a um curso/ nível, se constantemente sua carga horária é alocada nesse ou em outro curso dependendo das necessidades institucionais?

Uma das apostas pode ser partilhada nesse trabalho. Está relacionada ao Programa de Pós-Graduação em Educação Profissional e Tecnológica (ProfEPT), um mestrado profissional nacional em rede, com 36 polos espalhados pelo Brasil (mais uma vez a capilaridade dos institutos foi elemento importante nesse processo), o qual objetiva formar servidores da rede federal de educação profissional no âmbito da discussão da temática da Educação Profissional e Tecnológica, além de ampliar essa discussão e reflexão para outros profissionais externos a rede. Com duas linhas de pesquisa - Práticas Educativas em EPT e Gestão e Organização do Espaço Pedagógico em EPT - tem sido alvo de interesse de muitos candidatos, chegando na sua primeira edição a alcançar a marca de 25 mil inscritos. Considerando a quantidade de polos, de docentes credenciados e de alunos a coordenação geral do ProfEPT optou por organizar semestralmente seminários nacionais de alinhamento teórico-prático. Um dos autores desse artigo, precisamente a autora, teve a oportunidade de participar do 10 seminário, realizado em 08 de março de 2017, na cidade de São Paulo, além de diversos convites aos polos por todo o Brasil, e a partir dessas interlocuções, observações e vivência da capilaridade, que apostamos que esse movimento de integração da rede, além da discussão sobre educação profissional nesse nível e volume, possibilitará a criação de parcerias, ampliação e fortalecimento da rede, mas essencialmente, promoverá um debate sobre a identidade de um Instituto Federal, que há muito deveria ter sido encaminhado pelos órgãos competentes (SETEC e CONIF) de maneira mais sistemática e contundente. Nos reconhecermos como rede, como instituições de Ensino-Pesquisa-Extensão, como algo distinto das universidades, mas tão efetivo quanto, é tarefa essencial e emergencial para a sobrevivência dos IF em um dos momentos mais "temerosos" de sua existência. 


\section{REFERÊNCIAS}

BOMFIM. Alexandre Maia do. O Convívio da educação superior com a educação básica nos Institutos Federais: perderemos essa oportunidade?. In: ANJOS, Maylta Brandão dos; RÔÇAS, Giselle (orgs). As políticas públicas e o papel social dos Institutos Federais de Educação, Ciência e Tecnologia. Série Reflexões. Volume 1. p. 77-116. Natal: Editora do IFRN, 2017. Disponível em: http://www.gptec.org/acervo/ReflexoesIFv1.pdf

BOURDIEU. Pierre. Bourdieu entrevistado por Maria Andréa Loyola. Rio de Janeiro: EdUerj, 2002. ANJOS, Maylta Brandão dos; RÔÇAS, Giselle. Intermediando memória, instituição e vivência: o IFRJ campus Nilópolis registrado em lembranças. In: PEREIRA, Marcus Vinicius; PASSOS, Marco Aurélio Louzada; BENTIN, Priscila Caetano (orgs). Série Reflexões na Educação. Volume 2. No prelo.

BRASIL. Lei n 11.892. Presidência da República. Casa Civil. Institui a Rede Federal de Educação Profissional, Científica e Tecnológica, cria os Institutos Federais de Educação, Ciência e Tecnologia, e dá outras providências. Disponível em: https://www.planalto.gov.br/ccivil_03/_ ato2007-2010/2008/lei/l11892.htm. 2008.

HOUAISS, Antônio; MELLO FRANCO, Francisco Manoel, VILLAR, Mauro de Salles. Grande Dicionário Houaiss. Disponível em https://houaiss.uol.com.br/pub/apps/www/v3-3/html/ index.php\#0. 2017.

PACHECO, Eliezer. Institutos Federais: uma revolução na educação profissional e tecnológica. Brasília/São Paulo: Fundação Santillana/Editora Moderna, 2011.

PISA. Brasil. 2016. Disponível em: http://www.oecd.org/pisa/PISA-2015-Brazil-PRT.pdf QUEVEDO, Marguarete de. Um olhar para o IFRS: concepções sobre a verticalização nos institutos federais de educação, ciência e tecnologia. Anais da Reunião Científica Regional da Anped-Sul. 24 a 27 de julho de 2016. UFPR. Curitiba, Paraná. 2016. Disponível em: http://www. anpedsul2016.ufpr.br/wp-content/uploads/2015/11/eixo21_MARGARETE-DE-QUEVEDO.pdf RÔÇAS, Giselle; BOMFIM, Alexandre Maia do. Educação Superior e Educação Básica nos Institutos Federais: avaliação da verticalização de ensino com seus gestores. Rede Federal de Educação Profissional, Científica e Tecnológica. ISSN: 2594-4827 Educação Profissional e Tecnológica em Revista, v. 1, n 1, 2017. Disponível em: http://ojs.ifes.edu.br/index.php/ept/ article/view/880/506

PEREIRA, Marcus Vinicius; Rôças, Giselle. 0 ensino de pós-graduação nos institutos federais. In: ANJOS, Maylta Brandão dos; RÔÇAS, Giselle (orgs). As políticas públicas e o papel social dos Institutos Federais de Educação, Ciência e Tecnologia. Série Reflexões. Volume 1. p. 160-178. Natal: Editora do IFRN, 2017. Disponível em: http://www.gptec.org/acervo/ReflexoesIFv1.pdf 